\title{
Efecto de diferentes virus sobre el rendimiento potencial de la papa y su interacción con el estado de brotamiento de tubérculos- semilla en la costa del Perú*
}

\author{
L. Bertschinger**; U.C. Scheidegger***; J. Muñoz ${ }^{* * * * ;}$ A. \\ Hidalgo $* * * * *$
}

\section{RESUMEN}

Los estudios se llevaron a cabo en la Costa Central del Perú (112m), en las campañas agrícolas 1987 y 1988. Se utilizó el cultivar mejorado Yungay sembrado a densidades tradicionales de 0.33 a $0.40 \mathrm{~m}^{2} /$ planta. Se compararon los rendimientos de parcelas enteramente sembradas con tubérculos-semilla de alta calidad o con tubérculos-semilla infectados secundariamente con PVX, PVX + PVS, PVX + APMV, PVX + PVY y APMV + PLRV. El PVX redujo el rendimiento hasta en $45 \%$, dependiendo del estado de brotamiento de los tubérculos-semilla. La merma en el rendimiento se hizo más evidente cuando los tubérculos-semilla estaban mal brotados.

Los virus transmitidos por áfidos (PVY y PLRV) redujeron aún más el rendimiento. La mayor reducción de rendimiento (53\%) se obtuvo con tubérculos-semilla infectados con APMV + PLRV. La metodología utilizada para romper el período de reposo de los tubérculos-semilla, permitió comparar los reactivos Bromoetano y Rindite y su efecto en la producción de papa. Rindite fue menos efectivo que Bromoetano en romper el período de reposo de los tubérculos. Los tubérculos-semilla tratados con Rindite produjeron menos que aquellos tratados con Bromoetano. La desventaja de los tubérculos-semilla tratados con Rindite se manifestó en mayor medida cuando la infección virótica fue más severa y cuando los tubérculos-semilla estaban mal brotados. La infección virótica influyó en el color de la piel de

\section{Aceptado para publicación: julio 12, 1995}

* Trabajo financiado por el proyecto Apoyo a la Producción de Semilla e Investigación en Papa para mejorar la Productividad de la Papa en el Perú (Convenio INIAA-CIP-Cotesu).

** Ing. Agr., Ph.D., Virólogo; Centro Internacional de la Papa (CIP), Apartado 1558, LimaPerú. Dirección actual: Centro Internacional de Mejoramiento de Maíz y Trigo (CIMMYT), Apdo. Postal 6-641, 06600 México, D. E, México.

*** Ing. Agr., Ph. D., Especialista en Producción de Semilla; Centro Internacional de la Papa (CIP), Apartado 1558, Lima, Perú. Dirección actual: Centro Internacional de Agricultura Tropical (CIAT), Projet CIAT, Boite Postal 259, Rutare, Rwanda.

**** B. C.; Facultad de Agronomía, Universidad Nacional del Centro del Perú, Huancayo, Perú.

***** Ing. Agr. M. Sc., Director Programa de Investigación en Papa (PIPA); Estación Experimental Agropecuaria Sta. Ana, Instituto Nacional de Investigación Agraria y Agroindustrial (INIAA), Perú. 
Yungay cuando los tubérculos-semilla estuvieron adecuadamente brotados, pero no lo hizo cuando éstos estaban muy o mal brotados. Se compararon los resultados con aquellos de estudios similares llevados a cabo en la Sierra Central del Perú y otros países.

Palabras claves adicionales: PVX, APMV, PVY, PLRV, Rindite, Bromoetano, color y tamaño de los tubérculos.

\title{
The Effect of Different Viruses On The Potential Yield of Potato and Its Interaction With Seed Tuber Sprouting In the Central Coast of Peru
}

\begin{abstract}
SUMMARY
These studies were carried out in the coastal area of Perú (112 m) during 1987 and 1988. The improved cultivar Yungay was planted at traditional densities such as $0.33-0.40 \mathrm{~m} 2 /$ plant. Yields were compared between plots planted with high quality seed tubers and those with tubers secondarilyinfected with PVX, PVX + PVS, PVX+APMV, PVX + PVY and APMV+ PLRV. PVX reduced tuber yield up to $45 \%$. The worse seed-tubers were sprouted, the higher the yield reduction. Aphid transmitted viruses (PVY and PLRV) produced higher yield reductions (a maximum of 53\% in the case of APMV + PLRV). The use of bromethane and Rindite for breaking seed tuber dormancy allowed for their comparison and to study their influence on tuber yield. Rindite did not break dormancy as good as bromethane. Yields of Rindite treated seed-tubers were lower than those of bromethane treated seed-tubers. The disadvantage of seed-tubers treated with Rindite, was even higher if virus infection was more intense or when the seed-tubers were badly sprouted. Tuber skin color was only affected by virus infection if the seed was fairly sprouted, but not in case of well sprouted or badly sprouted tubers. These results were compared with published results of experiments carried out in the Peruvian central highlands and in other countries.
\end{abstract}

Additional index words:

PVX, APMV, PVY, PLRV, Rindite, Bromethane, tuber color and size. 


\section{INTRODUCCIÓN}

En el Perú, la papa se produce en diferentes zonas agroecológicas bajo distintas condiciones climáticas (Tabla 1). La mayoría de los agricultores siembran papa en la sierra, principalmente para autoconsumo, mientras que en la costa la papa se siembra para abastecer los mercados de las ciudades.

Tabla 1. Promedios mensuales de datos climatológicos selectos de 1987/88 de diferentes zonas productoras de papa en el Perú.

\begin{tabular}{ccccccc}
\hline Zona & Lugar & $\begin{array}{c}\text { Altura } \\
(\mathrm{m})\end{array}$ & $\begin{array}{c}\text { Campaña } \\
\text { principal }\end{array}$ & $\begin{array}{c}\text { Temp. } \\
\left({ }^{\circ} \mathrm{C}\right)^{\mathrm{a})}\end{array}$ & $\begin{array}{c}\text { Hum. } \\
\text { rel. }(\%)^{\mathrm{a})}\end{array}$ & $\begin{array}{c}\text { Precipit. } \\
(\mathrm{mm})^{\mathrm{b})}\end{array}$ \\
\hline \multirow{3}{*}{ S. Central } & Huancayo & 3,250 & Oct.-Abril & 14 & 68 & 114 \\
& Chicche & 4,000 & Oct.-Abril & 8 & 81 & 554 \\
C. central & Cañete & 250 & Abril-Dic. & 20 & 80 & 0.4 \\
\hline
\end{tabular}

a) Promedios de mínima y máxima diarias en los meses indicados.

b) Promedio mensual en los meses indicados

El Programa Nacional de Investigaciones en Papa (PIPA) del Instituto Nacional de Investigación Agraria y Agroindustrial (INIAA) del Perú, conduce un proyecto con el objetivo de incrementar la productividad de la papa que escasamente rinde 8 t/ha (6). La producción y distribución de tubérculos-semilla de alta calidad sanitaria y fisiológica, es una de las estrategias claves del proyecto (5). Los resultados de numerosos experimentos a nivel de finca en la sierra central del Perú indican que los tubérculos-semilla de alta calidad producidos por el proyecto, rinden más que aquellos del mismo cultivar producidos por el agricultor según sus métodos tradicionales (14). Comúnmente se supone que la merma en producción, observada con tubérculos-semilla de baja calidad, se debe principalmente a infecciones viróticas; pero existen pocas investigaciones en la región andina que demuestran el efecto negativo de los virus en la producción de la papa $(7,13)$. Hasta el momento no se han publicado resultados de trabajos que comparen este efecto bajo condiciones climáticas contranstantes en la región andina; al contrario existen suposiciones sobre el efecto de los virus, que no se comprobaron por datos experimentales en la zona respectiva. Existe por ejemplo la idea generalizada que las plantas infectadas producen más tubérculos pequeños que las sanas, o que el cultivar mejorado Yungay (S. tuberosum ssp. tuberosum x S. tuberosum spp. andigena) en caso de ser degenerado por efecto de los virus, produce tubérculos de color rojizo (observaciones personales), debido a que el color rosado de los ojos se extiende sobre casi toda la superficie del tubérculo, en lugar de la piel normalmente blanquecina de este cultivar. 
Es necesario conocer más sobre la importancia que tienen los virus para la producción de papa bajo las condiciones climáticas contrastantes del Perú, a fin de adaptar mejor las estrategias de producción y distribución de tubérculossemilla. Se consideran como importantes los siguientes virus: PVX, PVS, APMV, APLV, PVY y PLRV (I).

Ya se han reportado estudios sobre el efecto de los virus en el rendimiento y tamaño de los tubérculos producidos por dos cultivares mejorados en la Sierra Central (15). En los trabajos presentados en esta publicación se ha estudiado en la Costa Central del Perú (112) el efecto de los virus y del estado de brotamiento del tubérculo-semilla sobre el rendimiento, tamaño y color de los tubérculos producidos y la interacción entre estos dos parámetros. La metodología utilizada para romper el período de reposo de los tubérculos-semilla permitió además comparar los reactivos Bromoetano y Rindite y su efecto sobre la producción de la papa.

\section{MATERIALES Y MÉTODOS}

Se consideran tubérculos-semilla de papa de alta calidad a aquellos provenientes de lotes con menos de $4 \%$ de tubérculos infectados con virus. Se compararon tubérculos semillas de alta calidad con otros infectados secundariamente con uno o dos virus. Al momento de la siembra tanto los tubérculos-semilla de alta calidad como los infectados tenían la misma edad fisiológica y provenían de la misma zona agroecológica. Se utilizó el cultivar mejorado Yungay, considerado el más importante durante los años que se llevaron a cabo estos estudios, el cual es mayormente sembrado en la sierra aunque también se siembra en la costa. El diseño experimental fue de bloques completos aleatorizados (BCA), con un tratamiento (calidad de tubérculos-semilla) y con tres a cuatro repeticiones. El manejo agronómico utilizado (labores culturales, aplicación de pesticidas, irrigación) fue el tradicional de las zonas en las cuales se sembró cada experimento. La fertilización en todos los experimentos fue de 180-180-180 kg/ha de $\mathrm{N}-\mathrm{P}_{2} \mathrm{O}_{5}-$ $\mathrm{K}_{2} \mathrm{O}$, respectivamente.

\section{Experimento 1}

Se compararon lotes de tubérculos-semilla de alta calidad con otros infectados con PVX, PVX+PVS y PVX+APMV. Los tubérculos-semilla para este experimento se cosecharon en mayo de 1987, en la EEA Sta. Ana, Huancayo (3,280 m). Antes de la siembra fueron tratados con Rindite y los brotes se analizaron por ELISA. El ensayo fue sembrado en julio de 1987 en Cañete (BCA, con cuatro repeticiones) en el terreno de subestación de la Estación Experimental Agropecuaria (EEA) de la Molina, Lima. Cada parcela consistió en cinco surcos de 21 plantas cada uno. La distancia entre surcos fue de $100 \mathrm{~cm}$ y entre plantas de $40 \mathrm{~cm}(0.40 \mathrm{~m} / 2 /$ lanta). 
La cosecha se realizó en diciembre cuando el cultivo estaba maduro y consistió en nueve plantas restantes, ubicadas en el centro de cada parcela $\left(0.40 \mathrm{~m}^{2 /}\right.$ planta).

\section{Experimento 2}

Se compararon tubérculos-semilla de alta calidad con otros clasificados en dos grupos infectados con PVX, PVX + PVY y APMV + PLRV. Los tubérculos-semilla se cosecharon en Huancayo en abril de 1988 en parcelas sembradas con tubérculos con infección comprobada por análisis del jugo de brotes con ELISA. Los tubérculos producidos en estas parcelas se mantuvieron después de la cosecha a temperatura ambiente y bajo luz difusa. Muestras de estos tubérculos y de los tubérculos de alta calidad, de la misma edad fisiológica, se trataron con Bromoetano o Rindite $\left(150 \mathrm{ml} / \mathrm{m}^{3}\right.$; volumen total; $\left.20^{\circ} \mathrm{C}\right)$, según tres diferentes métodos para romper el período de reposo. Luego del tratamiento se les almacenó en la oscuridad a $20^{\circ} \mathrm{C}$. La dosis empleada para ambos productos fue menor que aquella reportada en la literatura (12), con el fin de minimizar su consumo, facilitar su manipuleo y evitar su toxicidad (Rindite es aún más peligroso que Bromoetano).

El experimento se sembró en el terreno de la EEA La Molina, en Lima. Los distanciamientos experimentales de siembra fueron de $100 \mathrm{~cm}$ entre surcos y 33 $\mathrm{cm}$ entre plantas $\left(0.33 \mathrm{~m}^{2} /\right.$ planta). La parcela experimental fue de cinco surcos con 15 plantas por surco. La cosecha se hizo en diciembre de 1988, de las 10 plantas centrales en cada uno de los tres surcos centrales de la parcela, se estudiaron los tres factores siguientes:

1) Estado de brotamiento de los tubérculos: se hicieron dos tratamientos básicos a los tubérculos: (a) se varió el número de días de almacenamiento antes del tratamiento de ruptura del reposo y (b) se probaron períodos (número de días) de incubación después del tratamiento para romper el reposo y al momento de la siembra. Se utilizaron tres combinaciones de (a) y (b), lo que resultó en tres lotes de tubérculos-semilla con estado de brotamiento distinto: 1 ) tubérculos "mal brotados" ( $\mathrm{a}=6$ días, $\mathrm{b}=27$ días); 2 ) tubérculos "regularmente brotados" ( $\mathrm{a}=40, \mathrm{~b}=15)$ y 3) tubérculos "bien brotados" ( $\mathrm{a}=40, \mathrm{~b}=30)$. En mayo 18, junio 9 y junio 26 se sembraron tres ensayos (BCA, con cuatro repeticiones), correspondiendo cada uno a un lote de tubérculos-semilla con diferente estado de brotamiento. Para hacer el seguimiento de los efectos causados por los diferentes estados de brotamiento de los tubérculos, se evaluó en un momento determinado de la campaña (Tabla 2), usando los tres surcos centrales, la fenología de las plantas en cada parcela. Los datos obtenidos se transformaron a porcentajes.

2) Reactivos para romper el período de reposo: Rindite y Bromoetano.

3) Infección virótica: Tubérculos de alta calidad y tubérculos infectados secundariamente con PVX, PVX + PVY y APMV + PLRV. 
La cantidad limitada de tubérculos infectados y otros factores no permitieron agrupar los tratamientos en un arreglo factorial completo. En la Tabla 3, se indica el número de repeticiones consideradas para el análisis de las diferentes combinaciones.

Se hizo el registro de rendimiento a la cosecha, color de la piel de los tubérculos (normal, rojizo) y peso por grupo según tamaño (consumo: > 100 g, "semilla": 50100 g, pequeño: 20-50 g y muy pequeño: $<20$ g).

Tabla 2. Datos importantes del manejo de los tubérculos-semilla y del manejo agronómico de los 3 experimentos, conducidos en Lima (1988) para evaluar la interacción de la ruptura del período de reposo y la infección virótica de la papa.

\begin{tabular}{|c|c|c|c|c|}
\hline \multirow[t]{2}{*}{$\begin{array}{l}\text { Brotamiento de los } \\
\text { Tubérculos }\end{array}$} & \multicolumn{2}{|c|}{$\begin{array}{c}\text { Almacenamiento (días) } \\
\text { Tratamientos }\end{array}$} & \multicolumn{2}{|c|}{ Días después de la siembr } \\
\hline & $a^{2}$ & $b^{3}$ & $\begin{array}{c}\text { Evaluación de la } \\
\text { fenología }\end{array}$ & $\begin{array}{l}\text { Corte } \\
\text { follaje }\end{array}$ \\
\hline "Malo" & 6 & 27 & 109 & 200 \\
\hline "Regular" & 40 & 15 & 90 & 181 \\
\hline "Muy bueno" & 40 & 30 & 73 & 195 \\
\hline
\end{tabular}

${ }^{1}$ Procedencia de los tubérculos-semilla: Huancayo (3,250 m). Se almacenaron los tubérculos bajo temperatura ambiental, luz difusa. Se rompió el período de reposo con Bromoetano o con Rindite $\left(150 \mathrm{ml} / \mathrm{m}^{3}\right.$ de volumen total).

${ }^{2}$ Días desde la cosecha hasta la ruptura del período de reposo.

${ }^{3}$ Días desde la ruptura del período de reposo hasta la siembra.

\section{Análisis serológicos por ELISA}

Para el análisis de los virus se usó el método ELISA descrito por Clark y Adams (3) con pequeñas modificaciones descritas por Gugerli (8), que incrementan la sensibilidad de la prueba. El virus se detectó en jugo de brotes utilizando anticuerpos monoclonales para PVY (IgG: $1.5 \mathrm{ug} / \mathrm{ml}$; conjugado: $2585 \mathrm{mU}$ enzima/ $0.645 \mathrm{ug}$ IgG/ml).

\section{Análisis estadístico}

Para el análisis de variancia se utilizaron las pruebas de F y de la Diferencia Límite Significativa (DLS) (2). Los datos en porcentajes, se transformaron con arcoseno o raíz cuadrada (9). Para la representación de resultados en tablas y figuras se transformaron a porcentajes los promedios de valores transformados. Los valores faltantes (robo de tubérculos) se trataron según la metodología descrita por Gómez y Gómez (9), si existían al menos dos de las cuatro repeticiones (Tabla 3). Se hizo un análisis conjunto de los tres ensayos conducidos en 1988, utilizando un modelo fijo para el factor "estado de 
brotamiento". Como fuente de error, correspondiendo a la variancia entre experimentos, se consideró la variancia acumulada entre las repeticiones dentro de cada experimento. Para el resto de los factores y sus interacciones se consideró como error experimental la suma restante de los cuadrados aplicando de tal manera los cálculos correspondientes a un análisis de experimentos conducidos en diferentes campañas (9).

Tabla 3. Número de repeticiones consideradas en el análisis estadístico para diferentes combinaciones de los factores "infección virótica", "reactivo para romper la dormancia" y "estado de brotamiento de los tubérculos- semilla" de los experimentos, conducidos en Lima, Perú (1988).

\begin{tabular}{llccc}
\hline $\begin{array}{c}\text { Infección } \\
\text { virótica }\end{array}$ & $\begin{array}{l}\text { Reactivo de } \\
\text { tratamiento }^{\text {a }}\end{array}$ & $6 / 27^{\mathrm{b}}$ & $\begin{array}{c}\text { Estado de } \\
\text { brotamiento 40/15 }\end{array}$ & $40 / 30$ \\
\hline \multirow{2}{*}{ alta } & Bromoetano & - & 3 & 3 \\
\multirow{2}{*}{ PVX } & Rindite & 3 & 3 & 4 \\
\multirow{2}{*}{ PVY+PVX } & Bromoetano & - & 3 & 3 \\
\multirow{2}{*}{ APMV+PLRV } & Rindite & 3 & 3 & 4 \\
& Bromoetano & - & - & - \\
& Rindite & - & - & 3 \\
& Bromoetano & - & 2 & 4 \\
\hline
\end{tabular}

1 Repetición: parcela de $5 \times 5$ m. (5 surcos, borde inclusive).

a Tratamiento con $150 \mathrm{ml} / \mathrm{m}^{3}$ de volumen total a $20^{\circ} \mathrm{C}$ para romper la dormancia.

b Días de almacenamiento entre cosecha y tratamiento por Bromoetano o Rindite (temperatura ambiental, Huancayo, luz difusa) / Días entre tratamiento y siembra en Lima $\left(20^{\circ} \mathrm{C}\right.$, oscuridad).

c Semilla con menos de 4\% de infección virótica.

\section{RESULTADOS Y DISCUSIÓN}

\section{Experimento 1}

El virus PVX solo, así como en combinación con PVS o APMV redujo significativamente el rendimiento en 1987, en Cañete (Tabla 4). Este resultado se discute conjuntamente con los resultados del Experimento 2. 


\section{Experimento 2}

1. El efecto de los diferentes virus sobre el rendimiento potencial

En los ensayos sembrados en La Molina (1988) PVX redujo también el rendimiento en forma significativa. En el peor caso, la producción con tubérculos-semilla infectados con PVX fue el 55\% comparada con la producción con tubérculos-semilla de alta calidad (Tabla 6). Cuando se usaron tubérculos-semilla bien brotados, la reducción del rendimiento por PVX no fue significativa (Tablas 5 y 6). Las combinaciones de los otros virus causaron una merma significativa independientemente de si la semilla estaba bien o mal brotada (Tablas 5 y 6). La mayor reducción del rendimiento se produjo con tubérculos-semilla infectados con APMV + PLRV (53\% de reducción, Tabla 6), seguida por PVX + PVY (46\%, Tabla 5). Las reducciones del rendimiento por efecto de las combinaciones de virus se explican por la menor producción de tubérculos grandes (> 100 g) así como de muy pequeños $(<20$ g, Tabla 5$)$. Además en el caso de los tubérculossemilla infectados con PVX + PVY, la proporción que ocuparon los tubérculos muy pequeños dentro de la producción total, fue mayor, en comparación con la de los tubérculos-semilla de alta calidad (5.1 y 207\%, respectivamente).

Considerando que 5\% de la producción no es mucho y que los tubérculossemilla infectados producen igual proporción de su rendimiento con tubérculos de tamaño para consumo y semilla, la selección de tubérculos muy pequeños no puede ser una estrategia eficiente de descarte de tubérculos infectados para mantener la calidad de los tubérculos-semilla en la costa.

Al momento de la evaluación de los parámetros fenológicos, la emergencia de las plantas en las parcelas sembradas con tubérculos-semilla infectados con APMV + PLRV era menor que en las otras. En general, en las parcelas con tubérculos-semilla viróticos, las plantas estaban más pequeñas que en las parcelas con tubérculos-semilla de alta calidad (Tabla 5). Sin embargo, se observó que el período vegetativo era el mismo para todas las categorías de tubérculos-semilla. Se concluyó que el menor rendimiento de los tubérculossemilla infectados se explica, por lo menos en parte, por un desarrollo más lento de las plantas viróticas comparadas con el de las plantas sanas. Una planta infectada demora más tiempo para tuberizar, pero cumple el mismo número de días hasta su madurez. Por lo tanto, tiene menos tiempo y menor área foliar disponible entre tuberización y madurez para interceptar la energía solar y transformarla en materia seca acumulada en los tubérculos.

Se sugiere que de esta manera se explica también el mayor peso de la fracción de tubérculos grandes en parcelas sembradas con tubérculos-semilla de alta calidad, porque una planta sana almacena más sustancias asimilables en los tubérculos formados por tener más tiempo y área foliar disponible para la producción y acumulación de éstas. 
Es posible comparar estos resultados con aquellos que el PIPA obtuvo de investigaciones conducidas en la Sierra Central del Perú (15), porque se utilizó el mismo cultivar y casi la misma metodología. En estos estudios se encontró que la infección con PVX en los tubérculos-semilla infectados no reduce el rendimiento, en siembras con densidades normales $\left(0.40 \mathrm{~m}^{2} /\right.$ planta), mientras que sí reduce el rendimiento hasta en $29 \%$ si se siembra a bajas densidades cuando ya no hay competencia entre las plantas individuales $\left(0.80 \mathrm{~m}^{2} / \mathrm{planta}\right)$. Por el contrario, el presente estudio demuestra que infecciones secundarias con PVX reducen significativamente el rendimiento en la costa, aún en campos sembrados a densidades normales ( $0.40-0.33^{2} /$ planta). Bajo condiciones de costa, las plantas crecen más rápidamente y alcanzan mayor altura que aquellas que crecen en la sierra. Se sugiere que el efecto del virus es más severo en la Costa que en la Sierra porque las condiciones favorecen más a la multiplicación y agresividad del virus.

Los virus severos afectan más la producción en la costa que en la sierra. La confección secundaria de APMV con PLRV redujo el rendimiento en la sierra en 49\%, en comparación con la producción obtenida con tubérculos-semilla de alta calidad (15), mientras que la reducción máxima en la costa fue de 53\% (47\% del rendimiento de tubérculos-semilla del alta calidad. Tabla 6).

Los tubérculos obtenidos en el cultivo en la sierra son más pequeños que en la costa. Se reportó que la fracción de mayor peso de la producción de tubérculossemilla de alta calidad en la sierra es de tamaño semilla ( $46 \%$ de la producción de tubérculos-semilla de alta calidad) (15), mientras que en la costa la mayor parte de la producción tenía tamaño consumo (67\%; Tabla 5). En la costa la fracción de tubérculos que se ve afectada por los virus es sobre todo la de tamaño para consumo, mientras que en la sierra es la de tamaño para semilla (15).

No se encontraron referencias sobre estudios detallados conducidos en otros países de la zona andina, que traten del daño de virus por infección secundaria. En los Estados Unidos, Europa (Holanda y Escocia) e Israel se han publicado resultados, obtenidos con cultivares de la ssp. tuberosum $(4,10,11,16)$. Las condiciones de la zona andina son distintas a las que prevalecen en estos países (clima, cultivares, raza de virus).

A pesar de estas diferencias, las cifras de las pérdidas por los diferentes virus tienen tendencias similares: daños casi indetectables por PVX $(4,17)$ y daños muy severos, hasta mayores que aquellos encontrados en el presente estudio, causados por PVY, PLRV y combinaciones de estos con PVX y otros virus. Se reportó por ejemplo, una reducción del rendimiento por PVX+PVY de $71 \%$ (4) y por PLRV de $50 \%$ o más $(10,11,16)$. Se concluyó que la interacción de las condiciones ambientales en la costa peruana con la infección virótica resulta, para cultivares mejorados de papa, con daños superiores a los que ocurren en la sierra y similares a aquellos reportados para países con clima continental y templado. 
Tabla 4. Efecto de la infección secundaria con diferentes virus, determinados por ELISA, sobre el rendimiento de papa (kg/planta), (cultivar Yungay, Cañete, 250 m, 1987).

\begin{tabular}{cccc}
$\begin{array}{c}\text { Semilla de alta } \\
\text { calidad }^{\text {a }}\end{array}$ & PVX & $\begin{array}{c}\text { Semilla infectada } \\
\text { PVX+PVS }\end{array}$ & PVX + APMV \\
\hline $0.84(100)$ a & $0.69(82) \mathrm{b}$ & $0.55(66) \mathrm{c}$ & $0.64(76) \mathrm{b}$
\end{tabular}

Distancia entre surcos: $100 \mathrm{~cm}$, entre plantas: $40 \mathrm{~cm}$.

Diseño de bloques completos randomizados al azar (4 rep., 9 plantas por parcela).

Promedios seguidos por la misma letra no son significativamente diferentes en la prueba de $\operatorname{LSD}(\mathrm{P}<=0.01)$.

Números en paréntesis indican el porcentaje del rendimiento de semilla de alta calidad

a) Semilla con menos de $4 \%$ de infección virótica.

Tabla 5. Efecto de infecciones secundarias con diferentes virus sobre el rendimiento y los parámetros del crecimiento de la planta y de la cosecha de papa (cultivar Yungay, semilla bien brotada, La Molina, Lima, 240 m, 1988).

\begin{tabular}{|c|c|c|c|c|c|}
\hline \multirow[t]{2}{*}{ Criterio } & \multicolumn{5}{|c|}{ Calidad de la semilla } \\
\hline & alta $^{\mathrm{a}}$ & PVX & $\mathrm{Y}+\mathrm{X}$ & $\mathrm{R}+\mathrm{MV}^{\mathrm{b}}$ & $\mathrm{P}^{\mathrm{C}}$ \\
\hline \multicolumn{6}{|l|}{ Rendimiento (t/ha) } \\
\hline Tubérculos consumo (> 100 g) & $\begin{array}{l}23.8 a \\
(100)\end{array}$ & $\begin{array}{c}21.8 \mathrm{a} \\
(91)\end{array}$ & $\begin{array}{l}9.8 \mathrm{~b} \\
(41)\end{array}$ & $\begin{array}{c}12.2 \mathrm{~b} \\
(51)\end{array}$ & $* *$ \\
\hline Tubérculos semilla (50- 100 g) & 7.9 & 7.5 & 6.6 & 5.4 & n.s. \\
\hline Tubérculos pequeños (20-50 g) & 2.9 & 2.9 & 1.9 & 2.6 & n.s. \\
\hline Tubérculos muy pequeños (<20 g) & $1.0 \mathrm{ab}$ & 1.3a & $0.9 \mathrm{ab}$ & $0.8 \mathrm{~b}$ & $*$ \\
\hline Rendimiento total & $\begin{array}{l}35.6 a \\
(100)\end{array}$ & $\begin{array}{c}33.5 a \\
(94)\end{array}$ & $\begin{array}{c}19.2 \mathrm{~b} \\
(54)\end{array}$ & $\begin{array}{l}21.0 \mathrm{~b} \\
(59)\end{array}$ & $* *$ \\
\hline Cáscara de color normal & $\begin{array}{l}21.2 \mathrm{a} \\
(100)\end{array}$ & $\begin{array}{l}24.4 a \\
(115)\end{array}$ & $\begin{array}{c}10.8 \mathrm{~b} \\
(51)\end{array}$ & $\begin{array}{c}13.9 \mathrm{~b} \\
(65)\end{array}$ & $* *$ \\
\hline \multicolumn{6}{|l|}{$\underline{\text { Porcentajes }}^{\text {d) }}$} \\
\hline del rendimiento total: & & & & & \\
\hline Tubérculos consumo & 67.0 & 65.1 & 52.3 & 58.1 & n.s \\
\hline Tubérculos semilla & 22.1 & 22.3 & 32.4 & 25.5 & n.s \\
\hline Tubérculos pequeños & 8.2 & 8.6 & 10.2 & 12.3 & n.s. \\
\hline Tubérculos mini & $2.7 \mathrm{~b}$ & $3.9 \mathrm{ab}$ & $5.1 \mathrm{a}$ & $4.0 \mathrm{ab}$ & $*$ \\
\hline Cáscara de color normal & 59.2 & 73.0 & 55.8 & 67.2 & n.s. \\
\hline de plantas sembradas Emergencia ${ }^{\mathrm{e}}$ & $84.2 \mathrm{a}$ & $84.1 \mathrm{a}$ & $77.5 \mathrm{a}$ & $54.2 \mathrm{~b}$ & $* *$ \\
\hline de plantas emergidas: $<30 \mathrm{~cm}$ & $61.5 \mathrm{a}$ & $99.1 \mathrm{~b}$ & $100.0 \mathrm{~b}$ & $98.1 \mathrm{~b}$ & $* *$ \\
\hline
\end{tabular}


Distancia entre surcos: $100 \mathrm{~cm}$, entre plantas: $33 \mathrm{~cm}$.

Números en paréntesis indican el porcentaje del mayor rendimiento en caso que las diferencias son significativas.

Bloques completos randomizados al azar (4 rep).

Valores seguidos por la misma letra en la misma línea, no son significativamente diferentes en la prueba de LSD $(\mathrm{P}<=0.05)$.

Semilla utilizada: Ver Tabla 3; Semilla tratada con Bromoetano $\left(150 \mathrm{ml} / \mathrm{m}^{3}, 20^{\circ} \mathrm{C}\right.$, oscuridad).

a Semilla con menos de 4\% de infección virótica.

b Semilla infectada con APMV y con PLVR.

c Significancia de la prueba F: * $\mathrm{P}<=0.05$, ** $\mathrm{p}<=0.01$.

d Transformación arcoseno o de raíz cuadrada para el análisis estadístico.

e Estos valores reflejan el desarrollo distinto para cada semilla el 2 de setiembre de 1988 (son 109, 90 y 73 días después de la siembra del experimento respectivo).

Tabla 6. Efecto de la infección secundaria con diferentes virus sobre el rendimiento de papa (tha), (cultivar Yungay, La Molina, Lima, 240 m, 1988).

\begin{tabular}{|c|c|c|c|c|}
\hline \multirow{2}{*}{\multicolumn{2}{|c|}{$\begin{array}{l}\text { Brotamiento de la semilla } \\
\text { (experimento) }^{\mathrm{a}}\end{array}$}} & \multirow{2}{*}{$\begin{array}{c}\text { Semilla } \\
\text { de alta calidad }^{\mathrm{b}}\end{array}$} & \multicolumn{2}{|c|}{ Semilla infectada } \\
\hline & & & PVX & $\mathrm{PLVR}+\mathrm{APMV}^{\mathrm{c}}$ \\
\hline "Malo" & (1) & 30.3 a (100) & $18.3 \mathrm{~b}(60)$ & $18.7 \mathrm{~b}(62)$ \\
\hline "Regular" & (2) & 38.6 a (100) & $21.2 \mathrm{~b}(55)$ & $18.2 b(47)$ \\
\hline "Bueno" & (3) & 34.6 a (100) & 33.2 a (96) & 22.2 b (64) \\
\hline
\end{tabular}

Distancia entre surcos: $100 \mathrm{~cm}$, entre plantas: $33 \mathrm{~cm}$

Bloques completos randomizados al azar (3 rep., 30 plantas por parcela).

Valores seguidos por la misma letra en la misma línea, no son significativamente diferentes en la prueba de $\operatorname{LSD}(\mathrm{P}<=0.05)$.

Número son paréntesis indican el porcentaje del rendimiento de semilla de alta calidad.

a Semilla utilizada en los 3 experimentos: ver Tablas 2 y 3; tratada con Rindite (150 ml/ $\mathrm{m}^{3} 3,20^{\circ} \mathrm{C}$, oscuridad).

b Semilla con menos de 4\% de infección virótica.

\section{Efecto del estado de brotamiento y su interacción con la infección virótica}

Los tubérculos semilla mal brotados produjeron en promedio 75\% en comparación a aquellos que estaban bien brotados (Tabla 7). Esto se explica por la menor proporción de tubérculos de tamaño consumo (> 100 g). 
La producción de los diferentes tamaños de tubérculos expresada en porcentaje del rendimiento total, no fue afectada por el estado de brotamiento de los tubérculos-semilla, pero sí por la infección virótica (Tabla 7) Los tubérculossemilla de alta calidad, en comparación con los infectados produjeron mayor porcentaje de su rendimiento con tubérculos mayores de 100 g $(69.4 \%$ y $<=54.7 \%$, respectivamente), mientras que los tubérculos-semilla infectados produjeron mayores porcentajes de tubérculos tamaño "Semilla: $(19.0 \%$ y >=26.5\%, respectivamente).

Tabla 7. Interacción entre estado de brotamiento de la semilla y calidad de la semilla (cultivar Yungay, La Molina, Lima 240 m, 1988).

\begin{tabular}{|c|c|c|c|c|c|c|c|c|c|}
\hline \multirow{2}{*}{\begin{tabular}{|l} 
Criterio \\
Rendimiento (t/ha) \\
\end{tabular}} & \multicolumn{3}{|c|}{ Brotamiento $^{\mathrm{a}}$} & \multicolumn{3}{|c|}{ Calidad $^{b}$} & \multicolumn{3}{|c|}{ Interacción } \\
\hline & malo & regular & bueno & $\mathrm{P}^{\mathrm{b}}$ & alta $^{c}$ & PVX & $\mathrm{R}+\mathrm{MV}^{\mathrm{d}}$ & $\mathrm{P}$ & $\mathrm{P}$ \\
\hline Tub. consumo (> $100 \mathrm{~g})$ & $\begin{array}{c}13.1 \mathrm{a} \\
(70)\end{array}$ & $\begin{array}{c}16.5 \mathrm{ab} \\
(89)\end{array}$ & $\begin{array}{c}18.6 \mathrm{~b} \\
(100)\end{array}$ & * & $\begin{array}{c}24.0 \mathrm{a} \\
(100)\end{array}$ & $\begin{array}{l}13.4 \\
(56)\end{array}$ & $\begin{array}{c}10.8 \mathrm{~b} \\
(45)\end{array}$ & $* *$ & $*$ \\
\hline Tub. semilla (50-100 g) & 5.9 & "'"5.3 & 7.3. & n.s. & 6.6 & 6.8 & 5.2 & n.s. & $*$ \\
\hline Tub. pequeños (20-50 g) & 2.5 & 2.7 & 2.9. & n.s. & 2.8 & 2.6 & 2.7 & n.s. & \\
\hline Tub. muy pequeños $(<20 \mathrm{~g})$ & 1.0 & 1.5 & 1.1. & n.s. & 1.1 & 1.4 & 1.0 & n.s. & n.s. \\
\hline Rendimiento total & $\begin{array}{c}22.4 \mathrm{a} \\
(75)\end{array}$ & $\begin{array}{c}26.0 \mathrm{ab} \\
(88)\end{array}$ & $\begin{array}{l}30.0 \mathrm{~b} \\
(100)\end{array}$ & $\begin{array}{l}\text { n.s. } \\
(100)\end{array}$ & $\begin{array}{c}34.5 \mathrm{a} \\
(70)\end{array}$ & $\begin{array}{c}24.2 \mathrm{~b} \\
(57)\end{array}$ & $19.7 \mathrm{~b}$ & $* *$ & n.s. \\
\hline Piel de color normal & 18.3 a & $15.3 \mathrm{~b}$ & $20.1 \mathrm{a}$ & n.s. & $\begin{array}{l}21.3 \mathrm{a} \\
(100)\end{array}$ & $\begin{array}{c}18.4 \mathrm{~b} \\
(86)\end{array}$ & $\begin{array}{c}14.1 \mathrm{c} \\
(66)\end{array}$ & $* *$ & $* *$ \\
\hline$\frac{\text { Porcentajes }}{\text { del rendimiento total: }}^{\text {d }}$ & & & & & & & & & \\
\hline Tub. consumo & 56.5 & 60.2 & 61.2. & n.s. & $69.4 \mathrm{a}$ & $53.8 \mathrm{~b}$ & $54.7 \mathrm{~b}$ & $\begin{array}{l}* * \\
*\end{array}$ & n.s. \\
\hline Tub. pequeños & 11.4 & 11.9 & 10.1. & n.s. & $\begin{array}{l}13.0 \mathrm{~d} \\
8.3\end{array}$ & 11.4 & 13.6 & n.s. & n.s. \\
\hline Tub. muy pequeños & 4.6 & 6.2 & 3.7. & n.s. & 3.3 & 6.0 & 5.3 & n.s. & n.s. \\
\hline $\begin{array}{l}\text { Piel de color normal } \\
\text { de p. sembradas: }\end{array}$ & $\begin{array}{l}80.8 \mathrm{a} \\
78.9 \#\end{array}$ & $\begin{array}{l}64.2 \mathrm{~b} \\
89.3 \#\end{array}$ & $\begin{array}{l}67.3 \mathrm{~b} \\
71.5 \#\end{array}$ & $\begin{array}{l}* * \\
\text { n.s. }\end{array}$ & $\begin{array}{l}68.4 \mathrm{a} \\
90.7 \mathrm{a}\end{array}$ & $\begin{array}{l}75.6 \mathrm{~b} \\
77.4 \mathrm{~b}\end{array}$ & $\begin{array}{l}72.3 \mathrm{ab} \\
71.5 \mathrm{~b}\end{array}$ & $\begin{array}{l}* \\
*\end{array}$ & $\begin{array}{l}* * \\
\text { n.s. }\end{array}$ \\
\hline de p. emergidas: $<30 \mathrm{~cm}$ & $45.9 \#$ & $74.8 \#$ & $89.7 \#$ & $* *$ & 39.8 a & $90.1 \mathrm{~b}$ & $80.6 \mathrm{~b}$ & $* *$ & n.s. \\
\hline
\end{tabular}

Distancia entre surcos: $100 \mathrm{~cm}$, entre plantas: $33 \mathrm{~cm}$

Números en paréntesis indican el porcentaje del mayor rendimiento en caso que las diferencias sean significativas.

Bloques completos randomizados al azar (3 rep).

Valores seguidos por la misma letra en la misma línea, no son significativamente diferentes en la prueba de LSD ( $\mathrm{P}<=0.05)$. 
${ }^{\text {a }}$ Semilla utilizada: ver Tablas 2 y 3; tratada con Rindite $\left(150 \mathrm{ml} / \mathrm{m}^{3} 3,20^{\circ} \mathrm{C}\right.$, oscuridad).

b Significancia de la prueba F: $* \mathrm{P}<=0.05, * * \mathrm{P}<=0.01$.

c Semilla con menos de $4 \%$ de infección virótica.

d Semilla infectada con APM V y con PLRV.

e Transformación arcoseno o de raíz cuadrada para el análisis estadístico.

\# Estos valores reflejan los diferentes estados de brotamiento de la semilla respectiva el 2 de setiembre de 1988 (son 109, 90 y 73 días después de la siembra del experimento respectivo).

Existe una interacción significativa entre la infección virótica y el estado de brotamiento para tubérculos grandes. Significa que el efecto del estado de brotamiento no es el mismo para diferentes calidades de tubérculos-semilla. Cuanto menor fue el brotamiento mayor fue el efecto de PVX, mientras que la infección conjunta con APMV + PLRV redujo con la misma severidad el rendimiento independientemente del estado de brotamiento de los tubérculossemilla (Figura 1).

Figura 1. La interacción entre infección virótica y el estado de brotamiento de los tubérculos-semilla de papa para el rendimiento (t/ha) con tubérculos mayores de $100 \mathrm{~g}$ (cultivar Yungay, en La Molina, Lima 240 m., 1988).

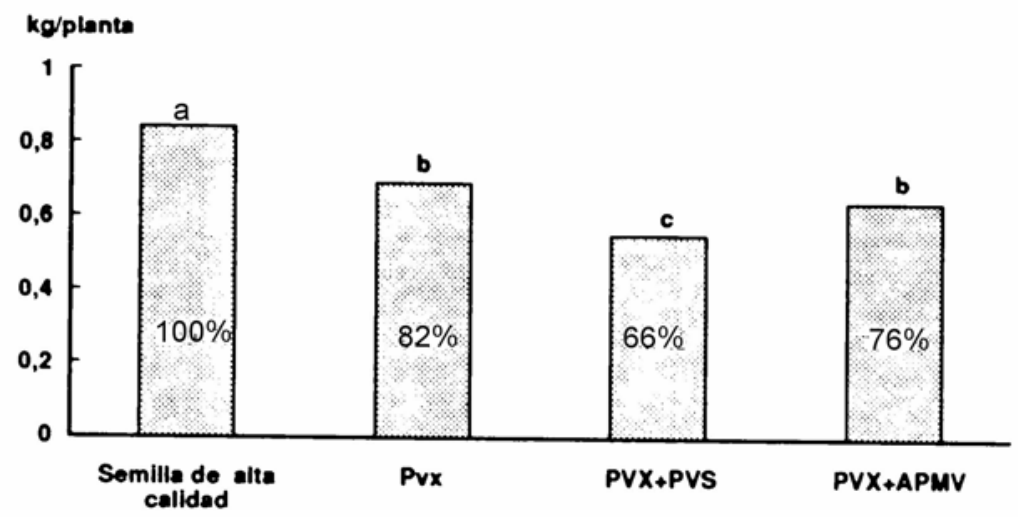

Valores con la misma letra y correspondiendo al mismo estado de brotamiento, no son significativamente diferentes en la prueba de $\operatorname{LSD}(\mathrm{P}=<0.05)$. Semilla tratada con Rindite, experimentos 1-3,3 rep., ver tabla 2 y 3. 
3. El efecto del reactivo para romper el periodo de reposo

En los ensayos con tubérculos-semilla brotados bien y regularmente (Tabla 2) se utilizaron tubérculos-semilas tratados con Rindite como con Bromoetano. Las parcelas sembradas con tubérculos tratados con Bromoetano estaban mucho más avanzadas en el momento de la evaluación de los parámetros fenológicos (Tabla 8). Esto quiere decir que Bromoetano en la dosis aplicada, fue más efectivo que Rindite en la ruptura del período de reposo. Así, estos dos reactivos actuaron como fuente adicional de variabilidad entre los estados de brotamiento de los tubérculos-semilla utilizados.

Tabla 8. Efecto del reactivo de tratamiento para romper la dormancia de la semilla sobre el rendimiento de la papa y su interacción con la calidad de la semilla (cultivar Yungay, La Molina, Lima, 240 m, 1988).

\begin{tabular}{|c|c|c|c|c|c|c|}
\hline \multirow[t]{2}{*}{ Criterio } & \multicolumn{3}{|c|}{ Tratamiento $^{\mathrm{a}}$} & \multicolumn{3}{|c|}{ Significancia (P) de } \\
\hline & $\mathrm{BE}$ & $\mathrm{RI}$ & $\mathrm{P}^{\mathrm{b}}$ & $\begin{array}{l}\text { Interacc. } \\
\text { Br.xTr. }\end{array}$ & $\begin{array}{l}\text { Interacc. } \\
\text { Ca.xTr. }\end{array}$ & $\begin{array}{c}\text { Interacc. } \\
\text { Br.xCa.xTr. }\end{array}$ \\
\hline \multicolumn{7}{|l|}{ Rendimiento (t/ha) } \\
\hline Tub. consumo (> 100 g) & 24.6 & 17.6 & $* *$ & * & * & * \\
\hline Tub. semilla (50-100 g) & 6.5 & 6.3 & n.s. & n.s. & n.s. & n.s. \\
\hline Tub. pequeños (20-50 g) & 3.4 & 2.8 & $*$ & n.s. & n.s. & n.s. \\
\hline Tub. muy pequeños (<20 g) & 1.3 & 1.3 & n.s. & n.s. & n.s. & n.s. \\
\hline Rendimiento total & 35.8 & 28.0 & $* *$ & * & n.s. & * \\
\hline Piel de color normal & 22.2 & 17.7 & $* *$ & $*$ & n.s. & n.s. \\
\hline \multicolumn{7}{|l|}{$\underline{\text { Porcentajes }}^{\mathrm{d}}$} \\
\hline \multicolumn{7}{|l|}{ del rendimiento total: } \\
\hline Tub. consumo & 68.0 & 60.7 & $*$ & * & * & n.s. \\
\hline Tub. semilla & 18.5 & 23.3 & $* *$ & n.s. & $*$ & n.s. \\
\hline Tub. pequeños & 9.8 & 11.0 & $* *$ & n.s. & $* *$ & n.s. \\
\hline Tub. muy pequeños & 3.7 & 5.0 & n.s. & n.s. & n.s. & n.s. \\
\hline Piel de color normal & 62.1 & 65.8 & n.s. & n.s. & $*$ & n.s. \\
\hline de p. sembradas: Emergencia & 96.2 & 80.4 & $* *$ & n.s. & n.s. & n.s. \\
\hline de p. emergidas: $<30 \mathrm{~cm}$ & 27.5 & 82.3 & $* *$ & $* *$ & n.s. & n.s. \\
\hline
\end{tabular}

Distancia entre surcos: $100 \mathrm{~cm}$, entre plantas: $33 \mathrm{~cm}$

a BE: Bromoetano, RI: Rindite (aplicación: $150 \mathrm{ml} / \mathrm{m3}, 20^{\circ} \mathrm{C}$, oscuridad).

b Significancia de la prueba F: * $\mathrm{P}<0.05$, ** $\mathrm{P}<0.01$.

c $\mathrm{Br}$.= brotamiento, $\mathrm{Tr} .=$ tratamiento de la semilla. Se consideraron los experimentos $2 \mathrm{y}$ 3 (ver Tabla 2 y 3; bloques completos randomizados al azar, 3 rep.)

d Ca. = calidad de la semilla: Semilla con $<4 \%$ de infección virótica, semilla infectada con PVX y semilla infectada con APMV+PLRV.

e Transformación arcoseno o raíz cuadrada para el análisis estadístico. 
El rendimiento de los tubérculos tratados con Bromoetano fue mayor que el de aquellos tratados con Rindite, sobre todo por la mayor proporción de tubérculos mayores de 100 g. (Tabla 8). El porcentaje que ocupa el peso de esta fracción en la producción total también fue mayor para los tubérculossemilla tratados con Bromoetano. Al contrario los porcentajes que ocuparon los pesos de tubérculos de tamaño semilla (50-100 g) y pequeños (20-50 g) fueron mayores para tubérculos-semilla tratados con Rindite en comparación con aquellos tratados con Bromoetano. Se obtuvieron interacciones significativas entre los factores "estado de brotamiento" y "reactivo para romper el periodo de reposo" y "reactivo para romper el periodo de reposo" y también entre "calidad de los tubérculos-semilla" y "reactivo" (Figura 2 y Tabla 8). Esto confirma las conclusiones obtenidas por el análisis de los datos bajo los aspectos de la infección virótica y el estado de brotamiento. Cuanto menos brotados estaban los tubérculos semillas (por ejemplo por efecto de un reactivo deficiente en romper el período de reposo), más se manifestaron los efectos negativos de características dañinas relacionadas con la calidad del tubérculo-semilla (estado de brotamiento, infección virótica).

Figura 2. La interacción entre estado de brotamiento de la semilla de papa y el reactivo para la ruptura artificial de la dormancia, para el rendimiento total (tha; cultivar Yungay, La Molina, Lima, 240 m, 1988)

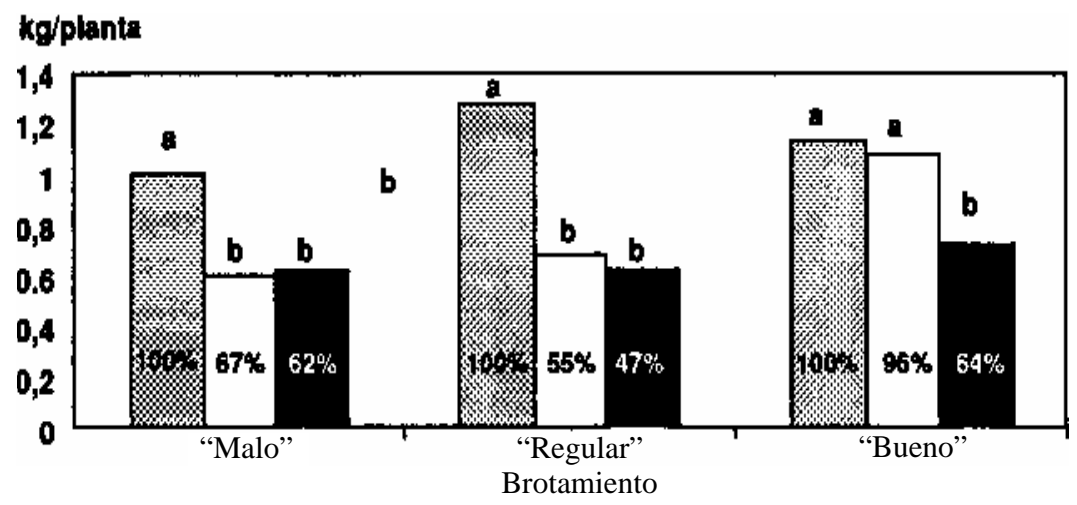

Valores con la misma letra y correspondiendo al mismo estado de brotamiento, no son significativamente diferentes en la prueba de $\operatorname{LSD}(\mathrm{P}<=0.05)$.

Experimentos 1,2 y 3 rep., ver tabla 2 y 3. 


\section{El color de la piel}

Cuando los tubérculos-semilla estaban bien brotados, el porcentaje del peso de tubérculos de color normal no fue afectado por la calidad de los tubérculos-semilla (Tabla 5). Esto significa que en el caso del cultivar Yungay no es posible distinguir por el color de su piel, tubérculos-semilla degenerados por el efecto de virus, de tubérculos. Se obtuvo una interacción significativa entre la calidad de los tubérculos-semilla utilizados y el estado de brotamiento con el porcentaje relacionado con el color de la piel (Tabla 7), indicando que en determinadas ocasiones puede haber diferencias. Los datos experimentales no permitieron determinar tendencias concluyentes entre este parámetro y la infección virótica y/o el estado de brotamiento. Por lo tanto se concluyó que los factores considerados no explican en su totalidad las causas del fenómeno de la piel rojiza del cultivar Yungay.

Figura 3. La interacción entre la infección virótica y reactivo para la ruptura artificial de la dormancia, para el rendimiento de papa con tubérculos mayores de $100 \mathrm{~g}$ (tha, cultivar Yungay, semilla bien brotada, La Molina, Lima, 240 m, 1988).

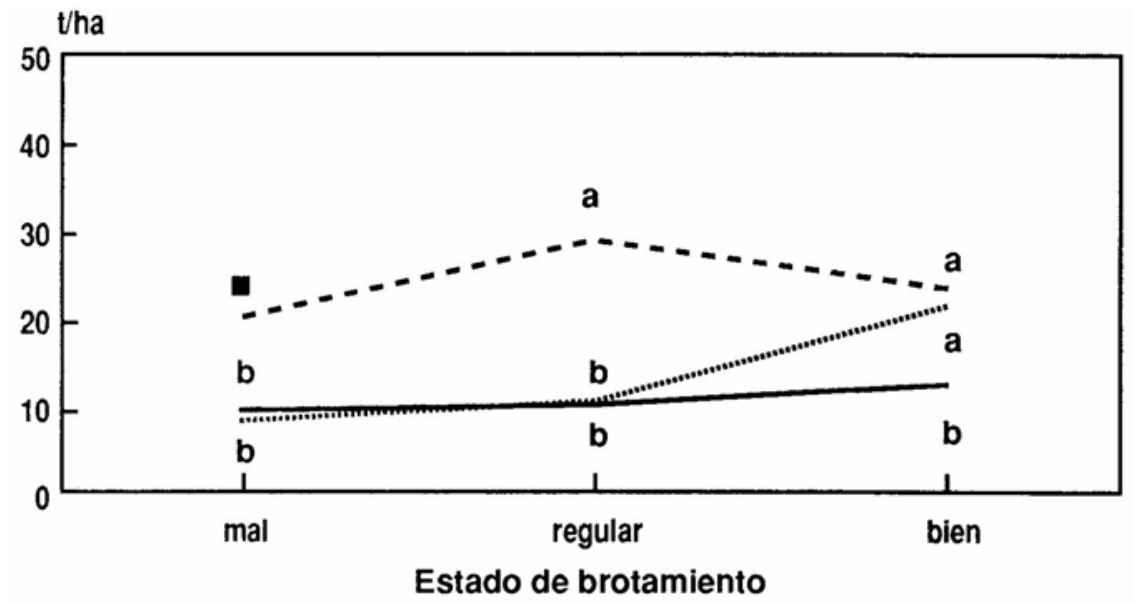

- - - Sem. de alta calidad ......... PVX $\quad$ PPMV + PLRV

Valores con la misma letra no son significativamente diferentes en la prueba de LSD ( $\mathrm{P}<=0.05)$.

Experimentos 2 y 3,3 rep., ver Tabla 2 y 3. 
Figura 4. La interacción entre infección virótica y estado de brotamiento de la semilla de papa, para el porcentaje del peso de la fracción con tubérculos de color blanquecino dentro de la producción total (cultivar Yungay en La Molina, Lima, 240 m, 1988).

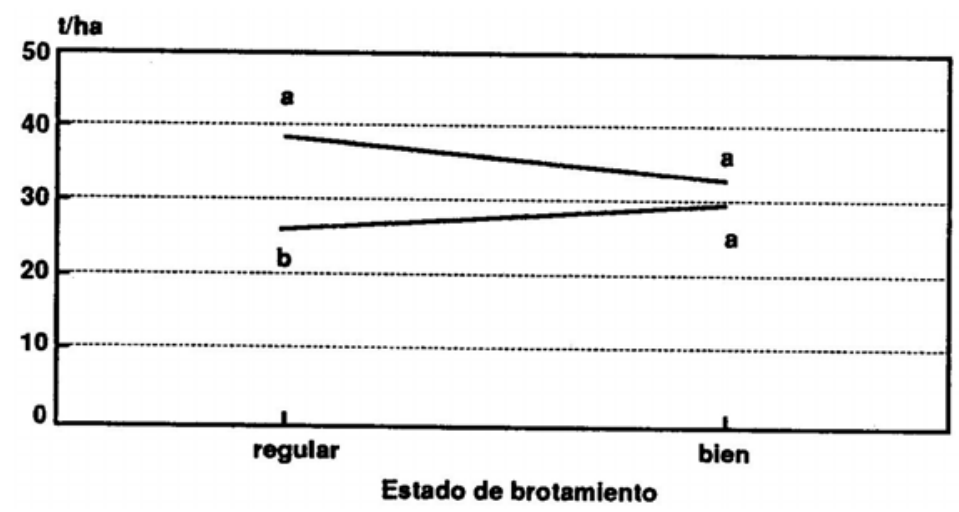

Porcentajes con la misma letra y correspondiendo al mismo estado de brotamiento, no son significativamente diferentes en la prueba de LSD para porcentajes transformados por arcoseno $(\mathrm{P}<=0.05)$.

Experimentos 1-3, 3 rep., ver Tabla 2 y 3.

* Valores retransformados de porcentajes transformados con arcoseno.

\section{REFERENCIAS BIBLIOGRÁFICAS}

1. Bertschinger, L.; Scheidegger, U. C; Luther, K.; Pinillos, O.; Hidalgo A. 1990. La incidencia de virus de papa en cultivares nativos y mejorados en la Sierra Peruana. Rev. Lat. de la Papa 3:62-79.

2. Calzada Benza, J. 1970. Métodos estadísticos para la investigación. Ed. Jurídica S.A. Lima, Perú.

3. Clark, M. F; Adams, A. N. 1977. Characteristics of the microplate method of enzyme-linked immunosorbent assay for detection of plant viruses. Journal of General Virology 34:475-783. 
4. Corsini, D. L.; Callihan, R. H.; Garner, J. G. 1983. The effect of Metribuzin interaction with potato viruses $\mathrm{X}$ and $\mathrm{Y}$ on potato foliage, yield and grade. Am. Potato J. 60:301-308.

5. Ezeta, F. N.; Scheidegger, U. C. 1985. Semilla básica: Un nuevo programa de producción y distribución para el Perú. CIP Circular 13(2): $1-5$.

6. FAO. 1987. World crop and livestock statistics. 1948-1985. Roma, Italia $159 p$.

7. Guerrero G., O.; Martínez, G. 1980. Evaluación de pérdidas ocasionadas en la variedad de papa ICA - Puracé por los virus "potato virus Y" y "potato leafroll virus". Fitopatología Colombiana 9: 33-40

8. Gugerli, P. 1986. Potato Viruses. In Bergmeyer (ed.), Methods of enzymatic analysis. Volume $\mathrm{Xi}$. Antigens and Antibodies 2. VCH Verlagsgesellschaft mbH, D-6940 Weinheim (Federal Republic of Germany). p. 430-446.

9. Gómez, K. A.; Gómez, A. A. 1976. Statical procedures for agricultural research with emphasis on rice. The International Rice Research Institute. Los Baños, Laguna, Philippines, p. 183-197.

10. Marco, S. 1984. Effect of potato leafroll virus on autumn potatoes in Israel. Potato Research 27: 155-162.

11. Marshall, B.; Barker, H.; Verrall, S. R. 1988. Effects of potato leafroll virus on the crop process leading to tuber yield in potato cultivars which differ in tolerante of infection. Ann. appl. Biol. 113:297-305.

12. Mc Donald, J. G.; Coleman, W. K. 1988. Are evaluation of bromethane in comparison to rindite for the post-harvest detection of potato virus $\mathrm{Y}$ in tubers by ELISA. Am. Potato J. 65:547-550.

13. Santos Rojas, J. 1985. Efecto del Virus del Enrollamiento de la Hoja de la papa (PLRV) sobre el rendimiento total de cuatro variedades de papa en el sur de Chile. Simiente 55: 38.

14. Scheidegger, U. C. 1989. Experimentos de semilla de papa en campos de agricultores y su aporte al desarrollo de un programa de semilla. En Ramakrishna, B. (ed.). Métodos y experiencias de investigación agrícola en campos de agricultores. VIH Seminario. IICA-BIDPRODIANDINO. Quito, Ecuador, p. 132-143.

15. Sheidegger, U. C.; Bertschinger, L.; Kuther, K.; Pinillos, O.; Muñoz, J.; Hidalgo, A. 1922. Efecto de diferentes virus sobre el rendimiento potencial de la papa en la Sierra Central del Perú. Rev. Lat. de la Papa 4. 
16. Van de Zaag, W. G. 1977. Betekenis van infectie van poters met virus op de opbrengst bij aardappelen. Landbouwkundig Tijschrift 89:154-157; tambiéen en: Bos, L. 1982. Crop loses caused by viruses. Crop Protection 1:263-282.

17. Wright, N.S. 1974. Combined effects of potato virus X and S on yield of Netted Gem and White Rose potatoes. Am. Potato J. 47: 475-478. 